\title{
Ethnic differences in the distribution of normally formed singleton stillbirths
}

\author{
P. B. TERRY \\ F.R.C.S.E., M.R.C.O.G. \\ R. G. CONDIE \\ M.D., M.R.C.O.G. \\ Department of Obstetrics and Gynaecology, Dudley Road Hospital, Birmingham B18 7QH
}

\begin{abstract}
Summary
The normally formed singleton stillbirth deliveries occurring in Dudley Road Hospital in 1979, 1980 and 1981 were classified according to the primary aetiology. There was a higher than normal stillbirth rate in the Indian group which was almost entirely accounted for by the increased number of stillbirths falling into the 'intrauterine death before labour' group.
\end{abstract}

KEY WORDS: stillbirths, blacks, whites, Asians.

\section{Introduction}

The perinatal mortality rate in Great Britain has been declining steadily. Although the causes of this fall are not known, many feel that improvements in social conditions are important factors. More comprehensive antenatal and intrapartum care may be contributary, although it has been suggested that these are of little consequence (Chalmers, Lawson and Turnbull, 1976; Kelso et al., 1978).

Despite the undoubted value of large scale epidemiological studies (Chamberlain et al., 1978) in the assessment of risk, they can mask important locally acting factors.

At Dudley Road Hospital, it was demonstrated that, in 1979, the crude perinatal mortality rate in the Indian population at $27 \cdot 5 / 1000$ was significantly $(P<0.02)$ higher than that of the European population at 13.5/1000 (Terry, Condie and Settatree, 1980). A further study (Terry and Condie, 1981) showed that for normally formed singleton deliveries, the perinatal mortality rates in the Indian group with birth weights of 2000-2999 $\mathrm{g}$ and 3000-3999 $\mathrm{g}$ were higher $(11 \cdot 5 / 1000$ and $6 \cdot 7 / 1000$ respectively) than in any of the other ethnic groups. The vast majority of these good weight normally formed perinatal deaths were stillbirths, normally formed neonatal deaths weighing more than $2000 \mathrm{~g}$ being very rare.

In an attempt to find the cause of these observed differences, a more detailed study of normally formed stillbirths occurring in singleton pregnancies in the years 1979-81 was undertaken.

\section{Patients and methods}

The case notes of the normally formed, singleton stillbirths were examined in detail. The cause of each stillbirth was categorized into one of 4 possible classifications. Those thought to be due to intrauterine growth retardation or to placental insufficiency or were unexplained were all classified in the same group known as intrauterine death (IUD) before labour' provided no other pathology was detected. The antepartum haemorrhage group included both placental abruption and placenta praevia. The hypertensive disease group included both pre-eclampsia and essential hypertension. The 'other' group included all the other causes found such as cord prolapse, intrapartum death and diabetes mellitus. The ethnic origin of the mother was obtained from the labour ward register.

\section{Results}

Although the Indian group had the highest total number of normally formed stillbirths (28) and the highest rate $(8.9 / 1000)$, the difference from the European group was not significant.

The distribution of the causes (Table 1) was similar in all the ethnic groups except for the increased number of Indian stillbirths falling into the intrauterine death before labour' group (difference from the European group: $P<0.01$ ) which accounted for the increased overall rate in this group. The slightly greater incidence of stillbirths due to hypertensive disease in the West Indians, although not unexpected, was not significant.

\section{Discussion}

The normally formed stillbirth group contains a large proportion of the perinatal deaths which, under ideal circumstances, may be regarded as preventable. The 'other' group of deaths contain those thought to 
TABLE 1. Ethnic distribution and the causes of stillbirths (rate/1000)

\begin{tabular}{|c|c|c|c|c|c|c|}
\hline $\begin{array}{l}\text { Ethnic } \\
\text { group }\end{array}$ & $\begin{array}{c}\text { Total } \\
\text { normally- } \\
\text { formed } \\
\text { singleton } \\
\text { deliveries }\end{array}$ & $\begin{array}{c}\text { IUD } \\
\text { before } \\
\text { labour }\end{array}$ & $\begin{array}{c}\text { Antepartum } \\
\text { haemorrhage }\end{array}$ & $\begin{array}{l}\text { Hypertensive } \\
\text { disease }\end{array}$ & Other & Total \\
\hline Indian & 3162 & $19(6 \cdot 0)^{*}$ & $6(1.9)$ & $3(0.9)$ & $0(0.0)$ & $28(8.9)$ \\
\hline Pakistani & 1599 & $5(3 \cdot 1)$ & $3(1.9)$ & $3(1.9)$ & $0(0.0)$ & $11(6 \cdot 9)$ \\
\hline West Indian & 1254 & $2(1 \cdot 6)$ & $3(2 \cdot 4)$ & $3(2 \cdot 4)$ & $1(0 \cdot 8)$ & $9(7 \cdot 2)$ \\
\hline European & 4918 & $10(2 \cdot 0)$ & $8(1.6)$ & $3(0.6)$ & $7(1.4)$ & $28(5 \cdot 7)$ \\
\hline Others & 467 & $1(2 \cdot 1)$ & $1(2 \cdot 1)$ & $0(0.0)$ & $1(2 \cdot 1)$ & $3(6.4)$ \\
\hline Total & 11400 & $37(3 \cdot 2)$ & $21(1 \cdot 8)$ & $12(1 \cdot 1)$ & $9(0 \cdot 8)$ & $79(6.9)$ \\
\hline
\end{tabular}

Difference for the European group: ${ }^{*} P<0.01$.

be due to conditions such as diabetes and cord prolapse, in addition to obviously avoidable intrapartum deaths. Maternal hypertension, from whatever cause, will always represent an increased risk to the fetus which may be reduced with careful management. Deaths due to antepartum haemorrhage, especially those due to placental abruption, often occur unexpectedly and many are unavoidable.

Those deaths classified in this study as intrauterine death before labour' represent the largest and most interesting group. There is often a suggestion of 'placental insufficiency' along with 'intrauterine growth retardation'; nevertheless the degree of growth retardation is frequently less than is observed in many live born infants. Many deaths in this group are unexplained and represent a considerable challenge to perinatal epidemiologists. The fact that such deaths appear to occur more commonly in Indians may help in the identification of possible aetiological factors.

\section{Acknowledgment}

Mr P. B. Terry is in receipt of a West Midlands Regional Healid Authority research grant.

\section{References}

Chalmers, I., Lawson, J.G. \& Turnbull, A.C. (1976) Evaluation of different approaches to obstetric care Part I and II. Jourmol of Obstetrics and Gynaecology, 83, 921.

Chamberlain, G., Philipp, E., Howlett, B. \& Masters, K. British Births 1970, Vol. 2, Heinemann, London.

Kelso, I.M., Parsons, R.J., Lawrence, G.F., Arora, EDMONDS, D.K. \& COOKE, I.D. (1978) An assessment continuous fetal heart rate monitoring in labour. America Journal of Obstetrics and Gynaecology, 131, 527.

TERRY, P.B. \& CONDIE, R.G. (1981) Ethnic differences in perina解 mortality. Postgraduate Medical Journal, 57, 790.

TERRY, P.B., Condie, R.G. \& SETTATREE, R.S. (1980) Analysis ethnic differences in perinatal statistics. British Medical Journg, 281, 1307. 